\title{
Vertigem como Manifestação Inaugural de Mieloma Múltiplo
}

Vertigo as an Initial Presentation of Multiple Myeloma

Luís Cardoso ${ }^{1}$, João Carlos Ribeiro ${ }^{1,2}$, Margarida Amorim¹, Mário Cruz ${ }^{1}$, Luís Silva ${ }^{1}$

Autor Correspondente: Luís Cardoso [luis.cardoso@gmail.com] Praceta Prof. Mota Pinto, 3000-075 Coimbra, Portugal

\section{RESUMO}

O mieloma múltiplo é uma neoplasia maligna de células B, caracterizada pela proliferação descontrolada e clonal de plasmócitos. O envolvimento intracraniano é incomum. A vertigem e o desequilíbrio são manifestações extremamente raras e habitualmente tardias de mieloma múltiplo com extensão intracraniana. Este trabalho tem como objetivo a apresentação de um raro caso de um doente com 55 anos com queixas de vertigem como manifestação inaugural de mieloma múltiplo da fossa posterior em estádio avançado, enfatizando os aspetos clínicos, diagnósticos e terapêuticas efetuadas.

PALAVRAS-CHAVE: Mieloma Múltiplo/diagnóstico; Neoplasias da Base do Crânio; Vertigem

\section{ABSTRACT}

Multiple myeloma is a malignant B cell neoplasm, characterized by uncontrolled and clonal proliferation of plasma cells. Intracranial involvement is uncommon. Vertigo and instability are extremely rare and usually late manifestations of multiple myeloma with intracranial extension. This study aims to present a rare case of a 55-year-old patient with vertigo complaints as an inaugural manifestation of advanced myeloma of the posterior fossa, emphasizing the clinical, diagnostic and therapeutic aspects.

KEYWORDS: Multiple Myeloma/diagnosis; Skull Base Neoplasms; Vertigo 


\section{INTRODUÇÃO}

O mieloma múltiplo (MM) é uma neoplasia maligna de células B, de etiologia desconhecida, caracterizada pela proliferação descontrolada e monoclonal de plasmócitos com invasão da medula óssea e lesões osteolíticas focais. Representa 1\% de todas as neoplasias malignas, sendo a segunda neoplasia hematológica mais comum. ${ }^{1}$ Estima-se que a sua prevalência na população seja de 5,6 em cada 100000 com média de idade ao diagnóstico de 70 anos. $^{2}$

Os sintomas mais comuns são a dor no esqueleto axial, astenia, insuficiência renal e infeções de repetição. Existem ainda outras formas de apresentações não convencionais, incluindo infeções bacterianas recorrentes por hipogamoglobulinemia ou hiperviscosidade sintomáticas com confusão, alterações da visão, cefaleias e vertigem. ${ }^{3}$ A vertigem como sintoma inicial de mieloma múltiplo é excecionalmente rara. ${ }^{4}$

O envolvimento extramedular ocorre em 7\% dos pacientes à apresentação e em 6\% no decorrer da doença, geralmente, sobre a forma de plasmocitoma isolado, no tecido conjuntivo adjacente ao esqueleto axial. ${ }^{5} \mathrm{~A}$ existência de plasmocitomas isolados da base do crânio, assim como a progressão intracraniana são extraordinariamente incomuns. ${ }^{4}$

O diagnóstico de MM requer a infiltração medular por plasmócitos e a existência de lesões de órgão-alvo: anemia, insuficiência renal, lesões ósseas e a hipercalcemia e/ou presença de imunoglobulina monoclonal no soro e/ ou na urina. ${ }^{2}$

Apesar de terapêuticas sistémicas agressivas - quimioterapia, anticorpos monoclonais e transplantação autóloga de células estaminais da medula óssea - e tratamentos locais como a radioterapia, o prognóstico dos pacientes com envolvimento do sistema nervoso central é extremamente reservado. ${ }^{6}$

Este trabalho documenta um caso de mieloma múltiplo intracraniano cuja manifestação clínica inaugural foi a vertigem.

\section{CASO CLÍNICO}

Homem de 68 anos com antecedentes de obesidade, hipertensão arterial, angina instável com colocação de stent farmacológico e gamapatia monoclonal de significado incerto (MGUS), polimedicado, que recorre à consulta de Otorrinolaringologia por quadro de desequilíbrio com dois meses de evolução e vertigem de início súbito. Ao exame físico observou-se um nistagmo multidirecional e ataxia. $\bigcirc$ teste de impulso cefálico foi ne- gativo bilateralmente e não apresentou desvio vertical bilateralmente no "alternate eye cover test". A avaliação de outros pares cranianos não revelou alterações. Sem queixas de diplopia ou sintomatologia auditiva. Realizou videonistagmografia (VNG), destacando-se: nistagmo evocado pelo olhar em todas as direções, ausência de nistagmo espontâneo e hiperreflexia bilateral nas provas calóricas. Pelos achados foi solicitada ressonância magnética (RM) cranioencefálica que identificou uma lesão expansiva extra-axial osteolítica ocupando a região occipital esquerda inferior medindo cerca de 3,5 $\mathrm{cm}$ (Fig. 1).

Analiticamente apresentava hemoglobina de 14,2 g/dL (referência: 13 a 17), creatinina 1,10 mg/dL (referência: 0,72 a 1,18), ausência de elevação de parâmetros inflamatórios e cálcio 8,9 mg/dL (referência: 8,8 a 10,6).

○ estadiamento da lesão demonstrou múltiplas lesões líticas ao longo da coluna vertebral e grelha costal, com
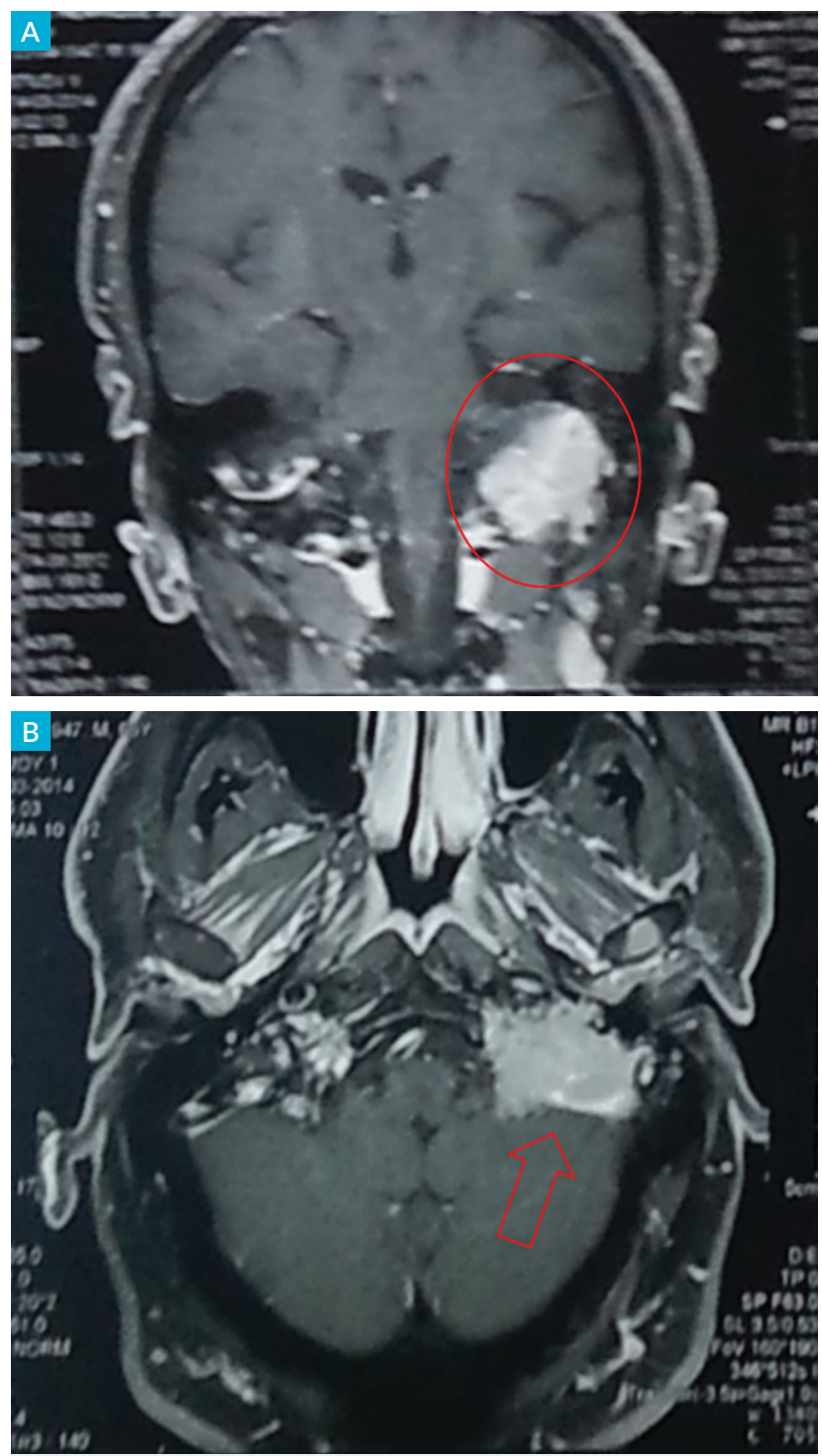

FIGURA 1. Ressonância magnética cranioencefálica - flair. Lesão expansiva extra-axial occipital esquerda: A - Corte coronal; B - Corte axial. 

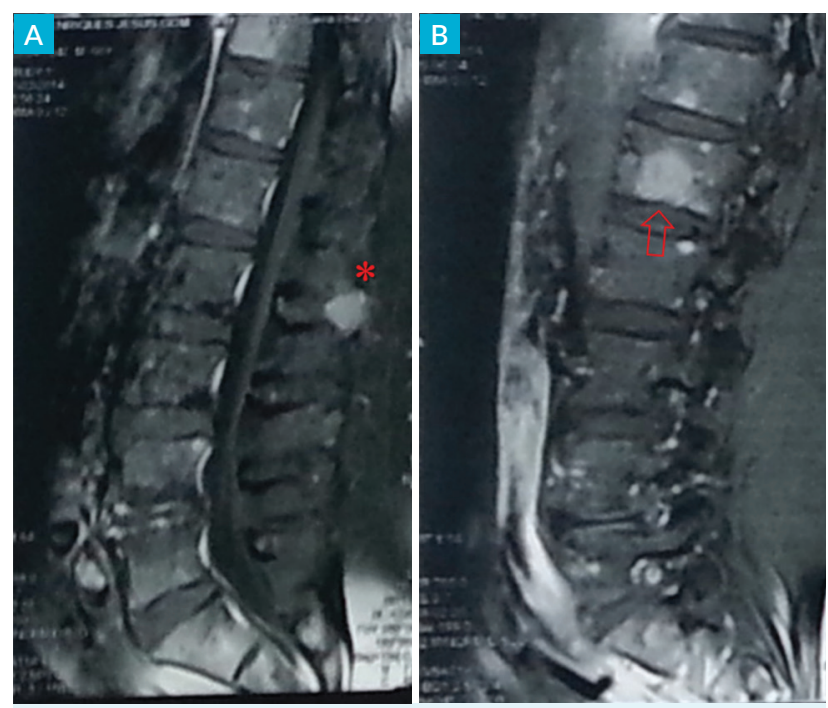

FIGURA 2. Ressonância magnética da coluna lombo-sagrada: T1 com contraste e supressão de gordura: A - Lesões ósseas múltiplas, de maior evidência na apófise espinhosa de L1 (*); B - corpo vertebral de L11 (seta).

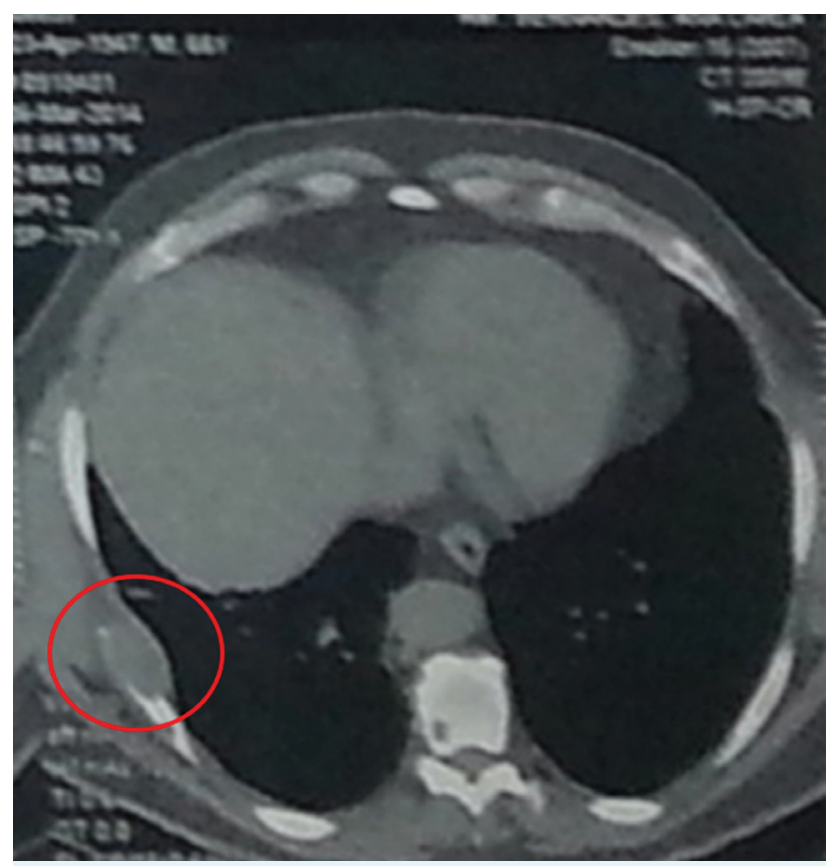

FIGURA 3. Tomografia computorizada toracoabdominal: lesão osteolítica da $8^{\text {a }}$ costela direita associada a massa de tecidos moles medindo $43 \times 27 \mathrm{~mm}$.

a de maior volume $(3 \mathrm{~cm})$ ao nível do oitavo arco costal direito (Fig. 2).

Realizou eletroforese de proteínas séricas que evidenciou elevação da fração gama cuja imunofixação permitiu identificação da elevação da IgG (21,2 g/L [referência: 7 a 16]) e aumento das cadeias leves lambda $(19,61 \mathrm{~g} / \mathrm{L}$ (referência: 2,99 a 6,99). Mielograma com 15\% plasmócitos. A biópsia da maior lesão costal confirmou diagnóstico de plasmocitoma (Fig. 3).

Perante o diagnóstico de MM IgG lambda de estádio avançado com múltiplos plasmocitomas, o paciente foi submetido a protocolo de quimioterapia com ciclofos- famida bortezomibe e dexametasona (CyBorD) em oito ciclos, assim como radioterapia dirigida à lesão intracraniana da dose de 40 Gy em 20 frações durante quatro semanas.

Durante o tratamento, complicado por apendicite aguda que obrigou a intervenção cirúrgica, o estado geral do doente foi-se degradando culminado em morte por paragem cardiorrespiratória ao final do oitavo ciclo do protocolo CyBorD.

\section{DISCUSSÃO}

O diagnóstico de MM pode ser dificultado pela clínica variável e apresentação tardia onde os sintomas clássicos de hipercalcemia, insuficiência renal, anemia ou lesões ósseas nem sempre estão simultaneamente presentes. Neste caso clínico, o diagnóstico foi realizado pela presença dos seguintes critérios do International Myeloma Working Group²: mielograma com plasmócitos $>10 \%$, diagnóstico histológico de plasmocitoma extramedular e múltiplas lesões osteolíticas do esqueleto.

A dor óssea é o sintoma mais comum, particularmente na região dorsal, ocorrendo em mais de 58\% dos pacientes, sendo detetadas lesões líticas em cerca de $80 \%$ dos pacientes à data do diagnóstico. ${ }^{7}$ A anemia é encontrada em $70 \%$ e a insuficiência renal por depósitos das cadeias leves ao nível dos túbulos coletores em 20\% - 40\%. A hipercalcemia é a manifestação menos frequente, ocorrendo em $13 \% .{ }^{8}$ O paciente em questão não apresentou anemia, alterações renais ou hipercalcemia nem referiu dor óssea apesar de múltiplos focos líticos.

A MGUS, entidade definida pela presença de imunoglobulinas monoclonais na urina e soro, na ausência de lesões alvo ou critérios para MM, precede virtualmente todos os casos de MM, com risco de transformação maligna de 0,5\% a 1\% ao ano., 2,8 doente em causa era seguido em Hematologia com controlo anual por MGUS estabilizada há 5 anos. Foi precisamente esta entidade que após a realização da RM levantou de imediato a hipótese de plasmocitoma intracraniano e que despoletou os restantes exames, culminando no diagnóstico de mieloma múltiplo. O envolvimento da base do crânio pelo MM resulta da disseminação óssea direta dos plasmocitomas ou de doença extramedular via hematogenea. ${ }^{5}$

O MM com apresentação intracraniana, é reportado em 3\% por grandes séries e geralmente observado em estádios avançados. ${ }^{9}$ Os sintomas típicos nestes casos são otalgia, cefaleia, massa retroauricular e paralisias cranianas múltiplas, sendo os pares mais afetados o II, III, IV e VI. No nosso caso não se observou qualquer 
compromisso desses pares cranianos e a sintomatologia principal que levou o paciente à consulta foi a vertigem.

A vertigem associada ao MM pode ser atribuída tanto a causas periféricas como centrais, consoante as estruturas envolvidas. Poderá ocorrer por eventual fenómeno de hiperviscosidade, decorrente do componente monoclonal sanguíneo excessivo, ou por compressão direta dos plasmócitos, ambas conduzindo a alterações isquémicas e consequente perda de função de estruturas do ouvido interno, do tronco cerebral ou do cerebelo. ${ }^{10} \mathrm{Al}$ terações da densidade entre a endolinfa e a cúpula são também descritas como causa de vertigem periférica em doentes com produção excessiva de componentes monoclonais. ${ }^{11}$ Muitas vezes, não é possível uma correta distinção entre vertigem de causa periférica e central apenas através da história clínica e exame à cabeceira, sobretudo na presença de sintomas ténues ou ausência de sintomatologia neurológica franca. De facto, o nistagmo evocado pelo olhar confirmado na VNG, assim como a hiperreflexia das provas calóricas, juntamente com a ataxia da marcha, apontavam para uma alteração central, particularmente ao nível do cerebelo, tendo sido posteriormente confirmada pelos exames imagiológicos.

Apesar da resposta ao tratamento com diminuição do componente monoclonal após vários ciclos de protocolo, as intercorrências, nomeadamente apendicectomia em doente leucopénico com longo período de sépsis, condicionou degradação do estado geral com falecimento do doente.

Este raro caso permite documentar que a vertigem rotatória de instalação súbita pode ser a manifestação inaugural e isolada de um mieloma múltiplo disseminado com extensão à fossa posterior. Devemos manter um alto índice de suspeição mesmo perante um exame otoneurológico fruste.

CONFLITOS DE INTERESSE: Os autores declaram não ter qualquer conflito de interesse na realização do presente trabalho.

FONTES DE FINANCIAMENTO: Não houve qualquer fonte de financiamento na realização do presente trabalho.

CONFIDENCIALIDADE DOS DADOS: Os autores declaram ter seguido os protocolos da sua instituição acerca da publicação dos dados de doentes.

PROTEÇÃO DE PESSOAS E ANIMAIS: Os autores declaram que os procedimentos seguidos na elaboração do presente trabalho estão em conformidade com as normas das comissões de investigação clínica e de ética, bem como da declaração de Helsínquia e da Associação Médica Mundial.

CONFLICTS OF INTEREST: The authors declare that they have no conflicts of interest.

FINANCIAL SUPPORT: This work has not received any contribution, grant or scholarship.

CONFIDENTIALITY OF DATA: The authors declare that they have followed the protocols of their work center on the publication of data from patients.

PROTECTION OF HUMAN AND ANIMAL SUBJECTS: The authors declare that the procedures followed were in accordance with the regulations of the relevant clinical research ethics committee and with those of the Code of Ethics of the World Medical Association (Declaration of Helsinki).

\section{REFERÊNCIAS}

1. Silva RO, Brandão KM, Pinto PV, Faria RM, Clementino NC, Silva CM, et al. Mieloma múltiplo: características clínicas e laboratoriais ao diagnóstico e estudo prognóstico. Rev Bras Hematol Hemoter. 2009;31:63-8.

2. Rajkumar SV, Dimopoulos MA, Palumbo A, Blade J, Merlini G, Mateos MV, et al. International Myeloma Working Group updated criteria for the diagnosis of multiple myeloma. Lancet Oncol. 2014;15:538-48.

3. Erikci A, Sayan O, Karagoz K, Velioglu M. Intracranial plasmacytoma as an initial presentation of multiple myeloma. Cent Eur J Med. 2010;5:541-3.

4. Joshi A, Jiang D, Singh P, Moffat D. Skull base presentation of multiple myeloma. Ear, Nose Throat J. 2011;90:3-6.

5. Palumbo A, Anderson K. Multiple Myeloma. N Engl J Med. 2011;364:1046-60.

6. Eslick R, Talaulikar D. Multiple myeloma: from diagnosis to treatment. Aust Fam Physician. 2013;42:684-8.

7. Lasocki A, Gangatharan S, Gaillard F, Harrison SJ. Intracranial involvement by multiple myeloma. Clin Radiol. 2015;70:8907.

8. Kyle RA, Therneau TM, Rajkumar SV, Offord JR, Larson DR, Plevak MF, et al. A long-term study of prognosis in monoclonal gammopathy of undetermined significance. N Engl J Med. 2002;346:564-9.

9. Silverstein A, Doniger D. Neurologic complications of myelomatosis. Arch Neurol 1963;9:534-44.

10. Andrews JC, Hoover LA, Lee RS, Honrubia V. Vertigo in the hyperviscosity syndrome. Otolaryngol Head Neck Surg. 1988;98:144-9.

11. Timothy C. Hain M. Positional Dizziness other than BPPV. 2017 [accessed Aug 2017]. Available from: http://www.Dizziness-and-balance.com. 